\title{
One-trial associative memory: Comparison of food-storing and nonstoring species of birds
}

\author{
NICKY S. CLAYTON and JOHN R. KREBS \\ Oxford University, Oxford, England
}

\begin{abstract}
Experiment 1 compared food-storing marsh tits and nonstoring blue tits, and Experiment 2 compared food-storing jays and nonstoring jackdaws, in a one-trial associative memory task. Birds obtained a reward by returning to the site where they had eaten part of the reward 30 min earlier. In "visible" versions, the reward was visible in Phase 1 but hidden in Phase 2 so that the bird had to search for it; in "hidden" versions, the reward was hidden in both phases. No species differences were found in performance in the visible version. However, in the hidden version, the 2 storers preferentially returned to rewarded sites, whereas nonstorers preferentially returned to sites that had been visited in Phase 1, irrespective of whether or not they contained a reward. This suggests that storers differ from nonstorers in the way they discriminate between remembered events.
\end{abstract}

Food-storing birds use an accurate, long-lasting memory to retrieve their stored food. They also have a larger hippocampus relative to the rest of the brain than do nonstorers, suggesting the hypothesis that food storers have a specialized memory ability and associated neural substrates (reviewed by Krebs, 1990, and Shettleworth, 1990). To test whether or not storing species have a memory ability that differs in quality or quantity from that of nonstorers, it is necessary to compare the two kinds of species in a task that does not involve storing food but that reveals the putative special memory features used by storing species to retrieve their hoards. Some of these comparative studies have used modifications of conventional tests of spatial memory, such as the radial-arm maze (Hilton \& Krebs, 1990) and delayed-matching or nonmatching-to-sample (DMTS or DNMTS; Healy \& Krebs, 1992a; Olson, 1991), whereas others have used tasks specifically designed to capture some essential features of the task of retrieving stored food, such as onetrial associative memory (Brodbeck, Burack, \& Shettleworth, 1992; Clayton \& Krebs, 1992) and the related procedure of "window shopping" (Krebs, Healy, \& Shettleworth, 1990; Shettleworth, Krebs, Healy, \& Thomas, 1990). The overall results of these studies involving both species in the Corvidae (e.g., Clark's nutcracker, Nucifraga columbiana) and Paridae (e.g., marsh tit, Parus palustris) have shown that the memory of stor-

This research was supported by a grant from the Agricultural and Food Research Council to N.S.C. and by grants from the Royal Society and the Science and Engineering Research Council to J.R.K. We are extremely grateful to David Wilson for technical assistance; without his skill and support, this work would not have been possible. We thank Dave Brodbeck, Rob Hampton, Sue Healy, Chris Hitchcock, Euan Macphail, Sara Shettleworth, Ian Todd, and Rob Willson for valuable comments on the manuscript, and David Gaffan, Nick Rawlins, and Edmund Rolls for helpful discussion. Correspondence should be addressed to N. S. Clayton, Edward Grey Institute, Department of Zoology, South Parks Rd., Oxford University, Oxford OX1 3PS, U.K. ers differs from that of nonstorers in some tasks but not in others, although the reasons for these differences are not yet clear (Brodbeck, 1994; Clayton \& Krebs, 1992; Healy \& Krebs, 1992a, 1992c; Hilton, 1991; Hilton \& Krebs, 1990; Krebs, Hilton, \& Healy, 1990; Olson, 1991).

In a one-trial associative memory task, a trial consists of two phases, separated by a retention interval. In Phase 1, the bird searches for and eats part of a piece of seed located in one of a number of potential trial-unique sites. In Phase 2, the bird's memory performance is tested by allowing it to search for the remainder of the seed. Accuracy of memory for the location of the partially eaten hidden food is measured by the number of errors (visits to other sites) before finding the seed: fewer errors imply more accurate peformance. The task has some resemblance to retrieval of stored food, in that it requires the bird to return to the site of a hidden seed after a single previous experience of the seed's location. It differs from food storing in at least two ways: (1) the bird does not place the seed in the site, and (2) in Phase 2, the bird has to remember a site where it obtained a reward as opposed to a site that contains a reward.

In an experiment comparing the performance of storers and nonstorers in this task, Clayton and Krebs (1992) found a difference between a storing and a nonstoring species. In Phase 2, storers selectively returned to the site with the remainder of the seed, whereas nonstorers returned to sites visited in Phase 1 whether or not they contained a seed. Consequently, the overall memory performance of the storing species (measured by the number of errors before finding the seed in Phase 2) was better than that of the nonstoring species. In their study, the seed was hidden in Phase 1 as well as in Phase 2, so that the birds typically searched in a number of places in Phase 1 before finding the seed. In Phase 2, the birds had to discriminate between sites that they had visited in Phase 1 and found to be empty (unseeded sites) and the one that had been visited and found to contain the seed 
(the seeded site). Clayton and Krebs (1992; see also Krebs, Healy, \& Shettleworth, 1990) hypothesized that the failure of nonstorers to discriminate between seeded and unseeded sites was the critical difference between the species. This view is supported by the fact that Healy and Krebs (1992c) (who compared the same two species as Clayton \& Krebs) and Brodbeck (1994) did not hide the seed in Phase 1, so that the bird usually looked in only one site in this phase. Therefore, this version of the task did not test the ability of birds to distinguish between seeded and unseeded sites. Both of these studies found no difference between storers and nonstorers in the number of errors before finding the seed in Phase 2.

These results suggest that a key difference between storers and nonstorers is in their ability to discriminate seeded and unseeded sites they have visited. However, the experiments referred to in the previous paragraph used procedures that differed in several ways so that it is impossible to isolate the effect of whether or not the seed was hidden in Phase 1. For example, Healy and Krebs (1992c) did not use trial-unique stimuli, whereas Clayton and Krebs (1992) did. This might have altered the aspect of memory tested by the task (remembering which one of a familiar set of stimuli is rewarded on any particular trial as opposed to learning on the basis of a single experience to associate a new stimulus with reward). Other studies have shown, both in birds and rats, that whether or not trial-unique stimuli are used can have important effects on memory performance (Brodbeck, Burack, \& Shettleworth, 1992; Rawlins, Lyford, Seferiades, Deacon, \& Cassaday, 1993).

The experiments reported in this paper were designed to test the hypothesis that food storers are better able to discriminate between seeded and unseeded sites, by direct comparison of the performance of storers and nonstorers in two treatments: with the seed visible or hidden in Phase 1. The results of previous studies (see above) lead us to predict that when the seed is hidden in Phase 1, storers will discriminate in Phase 2 between the site where they obtained a reward in Phase 1 (the seeded site) and the other sites they visited (unseeded sites), whereas nonstorers will discriminate only between visited sites (with or without a seed) and other sites. As a consequence, in the hidden treatment, storers should make fewer errors in finding the seed in Phase 2. In the visible treatment, the birds do not face the problem of discriminating in Phase 2 between seeded and unseeded sites, because normally only one site (the seeded site) is visited in Phase 1. We therefore expect the difference between storers and nonstorers in overall memory performance to be much reduced or absent in this treatment.

Experiment 1 compared the performance of two members of the Paridae: the storing marsh tit and nonstoring blue tit. Experiment 2 compared two members of the Corvidae, a family in which previous workers have found differences between species in storing behavior (Balda \& Kamil, 1989; Kamil, 1990), hippocampal anatomy (Healy \& Krebs, 1992b), and memory (Balda
\& Kamil, 1988; Kamil, Balda, \& Olson, in press; Olson, 1991). The corvid species compared here were the foodstoring jay, Garrulus glandarius (Bossema, 1979), and the nonstoring jackdaw, Corvus monedula (Henty, 1975). Jays' behavior was predicted to be similar to that of marsh tits; jackdaws' behavior was predicted to resemble that of blue tits. Food storing evolved independently in the Paridae and Corvidae, so the two comparisons described here are independent tests of whether or not food storers and nonstorers differ in their memory (Krebs, Sherry, Healy, Perry, \& Vaccarino, 1989).

Although the experiments reported here are concerned with behavioral differences between storing and nonstoring species, a major objective of the comparative study of memory in these species is to understand the relationship between differences in memory and differences in hippocampal anatomy (Krebs, 1990). In the Discussion section, we will therefore consider how any observed differences in memory might relate to hippocampal function.

\section{METHOD}

\section{Birds and Housing Conditions}

The subjects were 24 wild-caught birds, all of which had similar experience in previous experiments. In Experiment 1, the subjects were 6 adult marsh tits (mean weight $=10.5 \mathrm{~g}$ ) and 6 adult blue tits (mean weight $=11.3 \mathrm{~g}$ ). In Experiment 2, the subjects were 6 adult jays (mean weight $=170 \mathrm{~g}$ ) and 6 adult jackdaws (mean weight $=220 \mathrm{~g}$ ). The birds were housed individually indoors in wire cages (Experiment 1 cages measured $0.44 \mathrm{~m}$ wide $\times 0.77 \mathrm{~m}$ long $\times 0.44 \mathrm{~m}$ high; Experiment 2 cages measured $0.62 \mathrm{~m}$ wide $\times 0.76 \mathrm{~m}$ long $\times 0.91 \mathrm{~m}$ high). Both the living and experimental rooms were maintained on a 10:14-h light:dark cycle. During the experiment, the birds were deprived of food overnight at 17:00 GMT (lights out) and given fresh food and water following each trial. The birds in Experiment 1 were tested in the morning at about 10:00, following about $3 \mathrm{~h}$ of daytime deprivation. Experiment 2 was conducted in the late morning-afternoon (starting at 13:00), following about $6 \mathrm{~h}$ of daytime deprivation, commensurate with the larger body size of the birds. The experiments took place in January and February 1993.

\section{Experimental Environment}

In Experiment 1, the birds were tested individually in a room, $3.5 \times 2.0 \times 2.8 \mathrm{~m}$, and observed through a one-way Plexiglas window. The room contained seven "peanut feeders" (Krebs, Healy, \& Shettleworth, 1990), which were hung from plastic mesh screens, measuring $1 \times 2 \mathrm{~m}$, attached to two adjacent walls of the room. Each peanut feeder consisted of a wooden block, measuring $9.0 \times 4.0 \times 15.0 \mathrm{~cm}$, with a sloping top. In the center of the face of each wooden block, there was a hole $(0.5 \mathrm{~cm}$ diameter $X$ $0.5 \mathrm{~cm}$ deep), which could contain a piece of peanut. This hole could be covered by a knot at the end of a short piece of string attached to the block to prevent the birds from seeing the seed without first removing the knot (Clayton, 1992b; Hampton \& Sherry, 1994). Four centimeters below the hole, there was a perch $(5.5 \mathrm{~cm}$ $\times 0.9 \mathrm{~cm}$ diameter), on which the bird could sit to examine the contents of the hole. The birds readily learned to pull the knot of string away from the hole to inspect the contents on trials when the seed was hidden. Each feeder was made visually unique on every trial by the addition or removal of colored adhesive paper shapes drawn from a very large pool. Although individual shapes were 
used on more than one occassion, the combinations were unique. The location of the feeders was also chosen at random from 400 possible coordinates on the two mesh walls so that locations differed on each trial (Brodbeck et al., 1992).

In Experiment 2, the corvids were tested individually in a room $(4.24 \times 2.80 \times 2.30 \mathrm{~m})$ and observed through a one-way Plexiglas window. This room also contained seven peanut feeders, but these were placed on the floor. Each peanut feeder consisted of a square metal tray, measuring $25.5 \times 25.5 \times 7.5 \mathrm{~cm}$, which was filled with sand. In the center of the tray was the cap of a $35-\mathrm{mm}$ film cannister, which could contain a peanut. In Phase 2 of a trial, and in Phase 1 of the "hidden" treatment (see below), the cap was hidden below the sand surface so that it could not be found without probing in the sand. Each feeder was made individually distinct by the presence of a vertical cylindrical landmark $(30 \mathrm{~cm}$ long $\times 5.5 \mathrm{~cm}$ diameter) inserted in to the tray. The landmarks were made visually unique on every trial by the addition or removal of adhesive colored paper shapes and randomly repositioned on each trial, as in Experiment 1.

\section{Training}

For both experiments, the training and testing protocols were essentially the same. During initial training, all seven sites contained pieces of peanut. Once the birds had learned to visit sites containing food, only one site was rewarded on each trial and trialunique sites were introduced. In the first experiment, marsh tits required a mean \pm standard error of $12.0 \pm 0.05$ days and blue tits required $12.0 \pm 0.1$ days of training following initial familiarization with the apparatus. In the second experiment, jays required a mean \pm standard error of $12.0 \pm 0.15$ days and jackdaws required $11.0 \pm 0.2$ days of training. The criterion performance for proceeding to the test trials was for each bird to visit the rewarded site within $5 \mathrm{~min}$.

\section{One-Trial Associative Memory Task}

In both Experiment 1 and 2, each trial consisted of two phases, separated by a retention interval of $30 \mathrm{~min}$. In Phase 1 , the bird searched for a piece of peanut in one of seven sites and was allowed to eat the peanut for $30 \mathrm{sec}$ after finding it. Feeding was interrupted by turning off the room lights. In Experiment 1, the tits pecked at the peanut in its hole during the $30-\mathrm{sec}$ feeding time, removing small pieces but leaving the remainder of the nut in place. The two corvid species lifted the accessible peanut piece out of the cap in one piece, but the remainder of the peanut was under transparent plastic cover so that it was visible but not pulled out in Phase 1. In Phase 2, the bird was allowed back in to the room where the piece of partially eaten peanut was hidden in the site where it had been found in Phase 1. A bird with perfect memory should return immediately to the site where it had partially eaten the peanut in Phase 1 without looking in any other sites, whereas a bird searching at random without revisiting should find the peanut on average on the fourth look (Healy \& Krebs, 1992c). We recorded the total number of visits, excluding revisits (which were very rare), that each bird made to find the peanut in both phases. A visit was counted as the bird perching on the wooden block and inspecting the contents of the hole (Experiment 1) or probing in the sand of one of the trays (Experiment 2).

The birds were tested in two different treatments. In the first, the peanut was visible in Phase 1 (visible treatment); in the second, the peanut was hidden in Phase 1 (hidden treatment). In both treatments, the peanut was hidden in Phase 2 to test for memory in relocating the partially eaten food. All individuals were given three trials of each treatment: half the birds of each species were tested on the visible treatment followed by the hidden treatment, and the remainder were tested in the reverse order. The birds were given one trial per day, and the order of testing on each day was randomized. Seven days elapsed between the two treatments: 2 days on which the birds were not tested, followed by 5 days of training.

\section{RESULTS}

\section{Performance in Phase 1}

Performance in the first phase should differ between the two treatments because, in the visible treatment, birds should fly straight to the feeder to eat a peanut, whereas, in the hidden treatment, they should search at random until they find the feeder containing the hidden peanut. In Phase 1 of the visible treatment, all four species differed significantly from random search, with most individuals finding the peanut on the first look (one-sample $t$ tests with $5 d f$ ) (marsh tits, $M \pm S E=$ $1.11 \pm 0.07, t=41.11, p<.001$; blue tits, $M \pm S E=$ $1.06 \pm 0.06, t=53.00, p<.001$; jays, $M \pm S E=1.06$ $\pm 0.06, t=53.00, p<.001$; jackdaws, $M \pm S E=1.17$ $\pm 0.07, t=24.88, p<.01)$. In Phase 1 of the hidden treatment, the birds did not differ significantly from random expectation (one-sample $t$ tests with $5 d f$ ) (marsh tits, $M=3.89, t=0.54, p=.61$; blue tits, $M=3.94$, $t=0.41, p=.69$; jays, $M=4.06, t=0.24, p=.82$; jackdaws, $M=3.89, t=0.38, p=.72$ ).

\section{Number of Looks to Find the Seed in Phase 2}

Figures $1 \mathrm{a}$ and $1 \mathrm{~b}$ show the mean \pm standard error of the number of sites visited before finding the seed in Phase 2 in Experiments 1 and 2, respectively. Random search is represented by the horizontal lines in Figures $1 \mathrm{a}$ and $1 \mathrm{~b}$. All species in both hidden and visible treatments made significantly fewer visits in Phase 2 than expected by chance (one-sample $t$ tests with $5 d f$ ). (Visible treatment: marsh tits, $t=16.00, p<.001$; blue tits, $t=12.87, p<.001 ;$ jays, $t=16.43, p<.001$; jackdaws, $t=8.67, p<.001$. Hidden treatment: marsh tits, $t=$ $16.10, p<.001$; blue tits, $t=4.71, p<.001$; jays, $t=$ 8.80, $p<.001$; jackdaws, $t=3.07, p<.01$.)

To examine how species and treatments differed with respect to overall memory performance, Experiments 1 and 2 were analyzed using an analysis of variance (ANOVA) with the mean number visits to find the seed in Phase 2 as the dependent variable, species as a between-subjects factor, and treatment as a repeated measure.

For Experiment 1, the ANOVA showed a significant effect of species $[F(1,10)=9.70, p<.01]$ and treatment $[F(1,10)=6.98, p<.02]$ and an interaction between treatment and species $[F(1,10)=9.030, p<.01]$. These results show that marsh tits required fewer visits to find the seed, that the treatments differed, and that the difference between species was more marked in one treatment than in the other. Inspection of Figure 1a shows that these three effects arose because marsh tits performed better than did blue tits (fewer visits to find the seed) in the hidden treatment. The equivalent analysis of Experiment 2 showed an effect of species $[F(1,10)=$ $4.75, p=.05]$, whereas the other effects were not sig- 
(a)

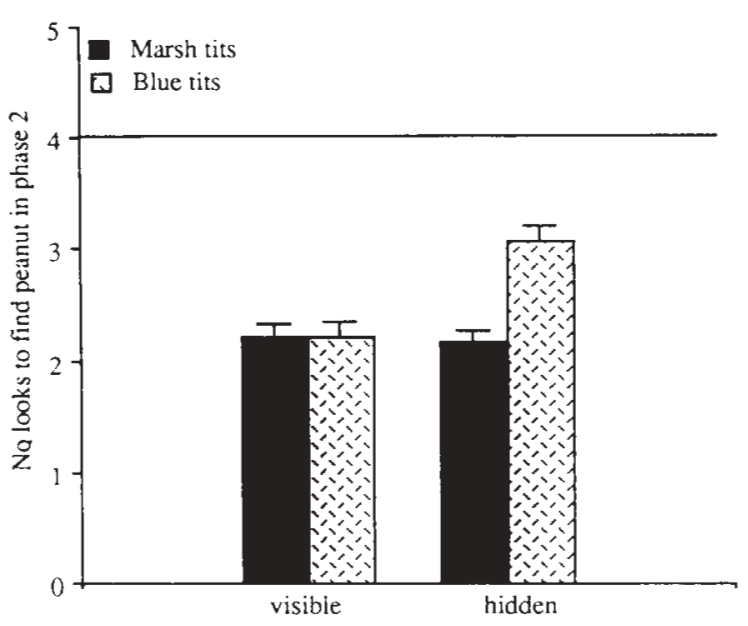

(b)

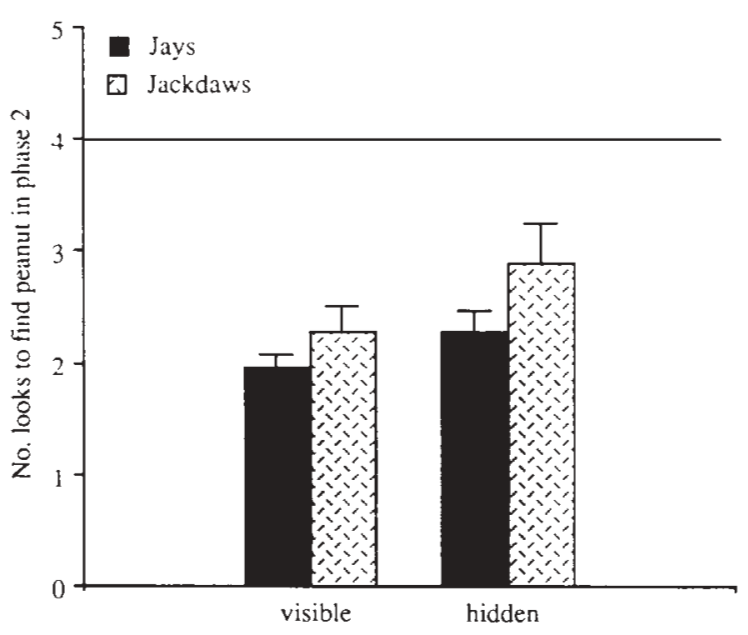

Figure 1. (a) Experiment 1 on marsh tits (food storers) and blue tits (nonstorers); (b) Experiment 2 on jays (food storers) and jackdaws (nonstorers). Mean and standard error of number of sites visited in Phase $\mathbf{2}$ before finding the remaining piece of peanut that had been found in Phase 1. In the visible version of the task, the peanut was visible in Phase 1 and hidden in Phase 2; in the hidden version, it was hidden in both phases.

nificant [treatment, $F(1,10)=3.13, p=.11$; interaction, $F(1,10)=0.27, p=.62]$. Figure $1 \mathrm{~b}$ shows that jays performed better than did jackdaws in both treatments. Inspection of the data suggest greater interindividual variability in Experiment 2.

In order to test for an overall comparison of storers and nonstorers, the results of the two experiments were combined in a single ANOVA with species nested within the category storer/nonstorer. There was a significant effect of storer versus nonstorer $[F(1,20)=12.02, p<$ $.003]$, an effect of treatment $[F(1,20)=8.50, p<.009]$, and an interaction between storer/nonstorer and treatment $[F(1,20)=4.3, p=.05]$. Thus, overall perfor- mance of storers was better than that of nonstorers; performance was better in the visible treatment than in the hidden treatment, and the performance of nonstorers was relatively worse in the hidden treatment than in the visible treatment.

\section{Discrimination Between Seeded, Unseeded, and Not-Visited Sites in Phase 2}

To test the hypothesis that food storers differ from nonstorers in the way they behave toward unseeded sites, we calculated the proportion of the total number of looks each bird made to these three types of site on each trial in the hidden version of the task. However, since birds may differ in the number of looks they make on different trials, performance based on the total number of looks in Phase 2 may bias the results (Shettleworth \& Krebs, 1982), because each bird can only visit one seeded site but from zero to several unseeded and notvisited sites. Thus, for example, in a trial in which the seed is found on the first look in Phase 2 there is a zero probability of visiting unseeded and not-visited sites, whereas in a trial in which the bird makes six looks before finding the seed, for one or both of these categories the probability is greater than zero. To take this problem into account, the observed proportions of looks to each type of site were compared with random expectation.

Since there are a total of seven sites in any one trial, and only one of these sites contains a piece of peanut, the probability of visiting the seeded site on the first look in Phase 2 is $1 / 7$ and the probability of visiting any other site (unseeded and not-visited) is $6 / 7$. The probability of visiting unseeded and not-visited sites in Phase 2 depends on the number of looks (out of a possible six) that a bird makes to unseeded sites in Phase 1 of that trial. If, for example, a bird found the peanut on the third look, having made two visits to unseeded sites, then the expected probability of visiting an unseeded site on the first look in Phase 2 is [probability of going to a site that is not the one with the seed $\times$ the probability that this site is unseeded] or $[6 / 7 \times 2 / 6]=2 / 7$. Similarly, the probability of visiting a not-visited site is $[6 / 7 \times(1-2 / 6)]=4 / 7$. Assuming no revisits, the expected probability of visiting a seeded site on the second look is $1 / 6$, of visiting an unseeded site is $[5 / 6 \times 2 / 6]$ $=5 / 18$, and of visiting a not-visited site is $[5 / 6 \times(1 \times$ $2 / 6)]=10 / 18$. As the number of looks increases, the probability of visiting the seeded versus an unseeded or not-visited site increases, until on the seventh look, the probability of visiting the seeded site is 1 and the probability of visiting an unseeded or not-visited site is 0 . Thus, the expected proportion of looks to the three types of site are given by the following formula: seeded site, $[1 /\{7-(n-1)\}]$; unseeded site, $[(1-1 /\{7-$ $(n-1)\}) \times(x / 6)]$; not-visited site, $[(1-1 /\{7-$ $(n-1)\}) \times(1-x / 6)]$; where $n=$ total number of looks in Phase 2, and $x=$ number of visits to unseeded sites in Phase 1 (Clayton, 1992a). This expected value was used to compute the observed-expected proportion of 
looks to each category of site, which is taken as a corrected value.

Figures $2 \mathrm{a}$ and $2 \mathrm{~b}$ shows the mean \pm standard error of the corrected proportion of looks to each type of site in Phase 2 of the hidden version of the task. The data for each experiment were analyzed with $t$ tests examining proportion of visits to the three kinds of site. In Experiment 1 , the marsh tits made a significantly higher proportion of looks to seeded sites than did blue tits $[t(10)=$ $12.57, p<.005]$ and a smaller proportion to unseeded sites $[t(10)=62.42, p<.0001]$; there was no difference for not-visited sites $[t(10)=1.35, p=.27]$. The corresponding analyses for Experiment 2 showed similar effects: jays made a higher proportion of visits to seeded sites $[t(10)=7.24, p<.02]$ and a lower proportion to unseeded sites $[t(10)=70.99, p<.0001]$, and there was no difference between species for not-visited sites $[t(10)=0.48, p=.51]$.

\section{DISCUSSION}

The key results may be summarized as follows: (1) In the hidden treatment of both experiments, storers discriminated between sites with the seed and other sites, whereas nonstorers discriminated between sites they had visited (whether or not they contained the seed) and other sites. (2) Combining the two experiments, storers made fewer errors in relocating the seed in Phase 2 of the hidden treatment, whereas there was no difference in this measure of memory performance in the visible treatment. This effect was statistically significant only in Experiment 1, perhaps because of greater interindividual variability in Experiment 2.

The results help to resolve an apparent inconsistency in previous literature in which Clayton and Krebs (1992) observed a difference in memory performance on marsh tits and blue tits, whilst Healy and Krebs (1992c) did not. The former study used the hidden treatment, and the latter used the visible treatment. The direct comparison of the two treatments reported here shows that this difference in procedure can have a significant effect on the outcome of the experiment.

More generally, the results suggest a difference in memory between storing and nonstoring species: storers are capable of more subtle discrimination among sites than are nonstorers. The fact that a similar effect appears in two phylogenetically independent comparisons (Paridae and Corvidae) supports the view that the observed difference is associated with food-storing rather than a chance difference between species.

Previous studies have shown several other differences in memory between storing and nonstoring (or less intensively storing) species of parids and corvids. Hilton and Krebs (1990), who compared storing and nonstoring tits, and Kamil et al. (in press), who compared corvid species depending to a greater or lesser extent on stored food, reported greater accuracy of performance of storers (in the tits) or intensive storers (in the corvids) following certain retention intervals in an

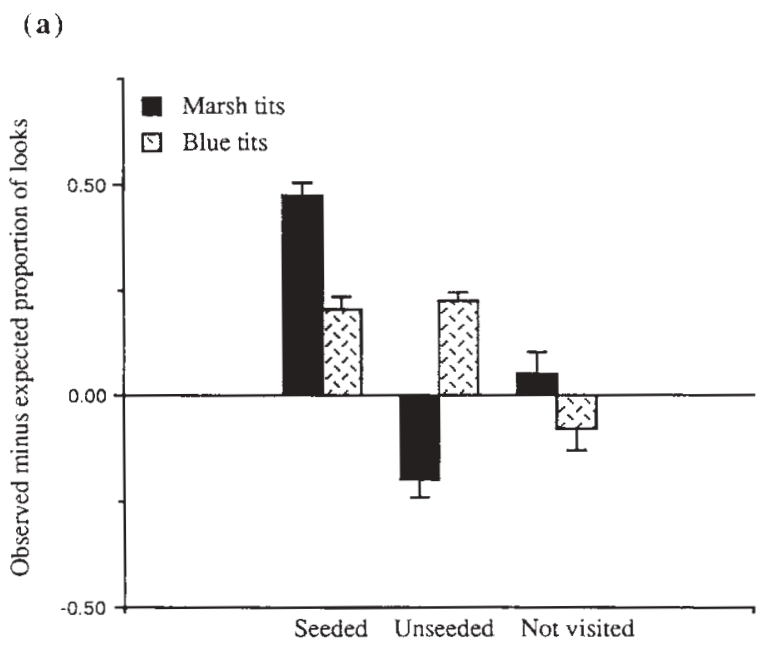

(b)

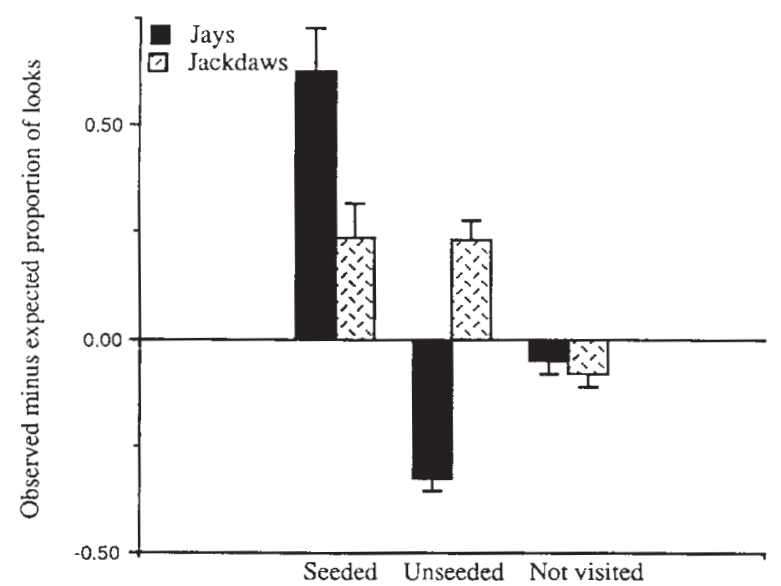

Figure 2. (a) Experiment 1 on marsh tits (food storers) and blue tits (nonstorers); (b) Experiment 2 on jays (food storers) and jackdaws (nonstorers). Mean and standard error of the observed minus expected proportion of visits in Phase 2 to the three categories of site based on behavior in Phase 1 of the hidden version of the task (see text for details).

open-field radial maze. Olson (1991) compared two corvid species, one an intensive storer and the other a less intensive storer, and showed that the intensive storer remembered for longer retention intervals in spatial delayed nonmatching to sample. Brodbeck (1994) and Clayton and Krebs (1994) used a one-trial associative memory task similar to the visible version of the task described in this study and showed that storers preferentially responded to spatial cues when position and object cues were dissociated by transforming the array, whereas nonstorers responded equally to the two kinds of cue. Experiments in which there were no differences in memory between storing and nonstoring species include color discrimination (Hilton, 1991) and delayed matching to sample with both spatial and object-specific cues available to solve the task (Healy \& Krebs, 1992a). 
As a working hypothesis, the results of these studies can be interpreted as showing that storing and nonstoring species differ in some aspect of spatial memory, although it is not yet clear whether the differences can be subsumed under a single dimension, such as greater accuracy and/or duration of spatial memory or greater attention to spatial cues by storing species. Storers are not better at all spatial memory tasks: in one reference memory task, they did not perform as well as nonstorers did (Hilton, 1991).

The present results can be encompassed within the framework of spatial memory differences by interpreting them as showing that food-storing species encode spatial information more accurately or in more detail than do nonstorers and hence are able to return to the seeded site, as opposed to the more general class of visited sites.

How does the hypothesis that storers and nonstorers differ in some aspect of spatial memory relate to differences in the relative size of the hippocampus? A number of experiments have shown that the avian hippocampus, like the rat and primate hippocampus, plays a role in processing and/or storing spatial memory. Hippocampal damage has been shown to impair the ability of homing pigeons to navigate home from novel release sites within the familiar area around the loft (Bingman, 1990), retrieval of stored food by black-capped chickadees (Parus atricapillus) (Sherry \& Vaccarino, 1989), spatial discrimination learning (Sherry \& Vaccarino, 1989), and spatial delayed nonmatching to sample (Good \& Macphail, in press-a). In contrast, at least some nonspatial tasks, such as color discrimination learning (Rice, 1992; Sherry \& Vaccarino, 1989), delayed matching to sample with repeated stimuli, and delayed nonmatching to sample with trial-unique stimuli (Good \& Macphail, in press-a) are unimpaired by hippocampal damage. Although spatial deficits are not the only impairments arising from hippocampal damage in birds (e.g., Good \& Macphail, in press-b; Reilly \& Good, 1989; Sandi, Rose, \& Patterson, 1992), it seems likely that a possible function of the avian hippocampus involves the encoding of some kinds of spatial information (although other hypotheses are also consistent with the data; Macphail, 1993). Thus, the specialization in hippocampal structure of food storers is at least consistent with the observed differences in memory in this and other comparative studies referred to above.

At the moment, there are too few studies of the effects of hippocampal lesions in birds to compare in detail with the effects in primates and rodents, where there is still much disagreement about whether hypotheses, such as processing declarative memory (Eichenbaum, Otto, \& Cohen, 1992; Squire, 1992) or reducing interference (Shapiro \& Olton, in press), have greater explanatory power than does the idea that the hippocampus is primarily concerned with spatial memory (Nadel, 1991). In part, the disagreements within the primate and rat literature may relate to differences in the precise areas lesioned (Gaffan, 1991; O’Boyle, Murray, \& Mishkin, in press) or to differences in test procedure (Rawlins et al., 1993). Lesions of the avian hippocampus carried out to date have been rather large and have not been related to the specific anatomical subdivisions of the area (Erichsen, Bingman, \& Krebs, 1991; Szekely \& Krebs, 1993).

Could the present results be explained in terms other than a difference in accuracy of spatial memory? An alternative framework is in terms of interference. Figure 2 shows that the nonstorers' memory for the site with the reward is not as good as that of storers, perhaps because nonstorers fail to discriminate between rewarded (seeded) and unrewarded (unseeded) sites that have been visited in Phase 1. In other words, nonstorers may remember both seeded and unseeded sites in the hidden version of the task, and so their memory load is higher and the chances of interference are therefore greater. This in turn could be linked to differences in hippocampal anatomy, using Shapiro and Olton's (in press) suggestion that a major function of the hippocampus is to reduce interference.

A further possibility is that the differences are not related to memory at all, but to confounding variables, such as motivation, perception, or motor skill. However, these are less likely to be important than in other comparative studies (Macphail, 1982), because the comparisons were between closely related species of similar morphology and behavior.

In terms of an adaptive specialization for retrieval of stored food, the difference between storers and nonstorers could be interpreted as relating to the difference between memory used in foraging and memory used in food storing. In searching for food, it is often important for an animal to remember recently visited sites. This ability, which might be used, for example, to avoid revisiting depleted sites before food supplies have regenerated, is probably widespread (e.g., Davies \& Houston, 1981; Gill, 1988; Kamil, 1978; Olton \& Samuelson, 1976). This is apparently the kind of memory shown by nonstorers in the present experiments, although here the response rule was to return to visited sites rather than to avoid them. In contrast, for an animal remembering the location of stored food, it is important to remember, amongst all the sites that have been visited, the small proportion that have been used for storing food. This capability might be the one revealed in the hidden task in the present experiments.

\section{REFERENCES}

BALDA, R. P., \& KAMIL, A. C. (1988). The spatial memory of Clark's nutcrackers (Nucifraga columbiana) in an analogue of the radial arm maze. Animal Learning \& Behavior, 16, 116-122.

BALDA, R. P., \& KAMIL, A. C. (1989). A comparative study of cache recovery by three corvid species. Animal Behaviour, 38, 486-495.

Bingman, V. P. (1990). Spatial navigation in birds. In D. S. Olton \& R. P. Kesner (Eds.), Neurobiology of comparative cognition (pp. 423-447). Hillsdale, NJ: Erlbaum.

Bossema, I. (1979). Jays and oaks: An eco-ethological study of a symbiosis. Behaviour, 70, 1-117.

Brodbeck, D. R. (1994). Memory for spatial and local cues: A comparison of a storing and a nonstoring species. Animal Learning \& Behavior, 22, 119-133.

Brodbeck, D. R., Burack, O. R., \& Shettleworth, S. J. (1992). 
One-trial associative memory in black-capped chickadees. Journal of Experimental Psychology: Animal Behavior Processes, 18, 12-21.

Clayton, N. S. (1992a). Lateralization and unilateral transfer of spatial memory in marsh tits. Journal of Comparative Physiology A, 171, 807-815.

Clayton, N. S. (1992b). The ontogeny of food-storing and retrieval in marsh tits. Behaviour, 122, 11-25.

Clayton, N. S., \& Krebs, J. R. (1992). Lateralization in Paridae: Comparison of a storing and a non-storing species on a one-trial associative memory task. Journal of Comparative Physiology A, 171, 807-815.

Clayton, N. S., \& Krebs, J. R. (1994). Memory for spatial and object-specific cues in food-storing and non-storing birds. Journal of Comparative Physiology A, 174, 371-379.

Davies, N. B., \& Houston, A. I. (1981). Owners and satellites: The economics of territory defence in the pied wagtail, Motacilla alba. Journal of Animal Ecology, 52, 621-634.

Eichenbaum, H., Otтo, T., \& Cohen, N. J. (1992). The hippocampus: What does it do? Behavioral \& Neural Biology, 57, 2-36.

Erichsen, J. T., Bingman, V. P., \& Krebs, J. R. (1991). The distribution of neuropeptides in the dorsomedial telencephalon of the pigeon (Columba livia): A basis for regional subdivisions. Journal of Comparative Neurology, 314, 478-492.

Gaffan, D. (1991). The spatial organization of episodic memory. Hippocampus, 1, 262-264.

GILL, F. B. (1988). Trapline foraging by hermit hummingbirds: Competition for an undefended renewable resource. Ecology, 69, 19331942.

Good, M., \& MacPhaIL, E. M. (in press-a). The avian hippocampus and short-term memory. Quarterly Journal of Experimental Psychology.

Good, M., \& MacphaIL, E. M. (in press-b). Hippocampal lesions in pigeons (Columba livia) disrupt reinforced pre-exposure but not overshadowing or blocking. Quarterly Journal of Experimental Psychology.

Hampton, R. R., \& Sherry, D. F. (1994). How cache loss affects choice of cache site in black-capped chickadees. Behavioural Ecology, 5, 44-50.

Healy, S. D., \& Krebs, J. R. (1992a). Delayed-matching-to-sample by marsh tits and great tits. Quarterly Journal of Experimental Psychology, 45B, 33-47.

Healy, S. D., \& Krebs, J. R. (1992b). Food storing and the hippocampus in corvids: Amount and volume are correlated. Proceedings of the Royal Society of London: Series B, 248, 241-245.

Healy, S. D., \& Krebs, J. R. (1992c). Spatial memory in tits: Recalling a single positive location. Animal Learning \& Behavior, 20 , 121-126.

HeNTY, C. J. (1975). Feeding and food-hiding responses of jackdaws and magpies. British Birds, 68, 463-466.

Hilton, S. C. (1991). A comparative study of spatial memory. Unpublished doctoral dissertation, Oxford University.

Hilton, S. C., \& Krebs, J. R. (1990). Spatial memory of four species of Parus: Performance in an open-field analogue of a radial maze. Quarterly Journal of Experimental Psychology, 42B, 345-368.

KAMIL, A. C. (1978). Systematic foraging for nectar by the amakihi, Loxops virens. Journal of Comparative Physiological Psychology, 92, 388-396.

KamiL, A. C. (1990). Spatial memory in seed-caching corvids. In G. H. Bower (Ed.), The psychology of learning and motivation (Vol. 26, pp. 1-25). New York: Academic Press.

KAMIL, A. C., BALDA, R. P., \& Olson, D. J. (in press). Performance of four seed-caching Corvid species in the radial-arm maze analog. Journal of Comparative Psychology.

Krebs, J. R. (1990). Food-storing birds: Adaptive specialization in brain and behaviour? Philosophical Transactions of the Royal Society of London: Series B, 329, 55-62.
Krebs, J. R., Healy, S. D., \& Shettleworth, S. (1990). Spatial memory of Paridae: Comparison of storing and non-storing species P. ater and P. major. Animal Behaviour, 39, 1127-1138.

Krebs, J. R., Hilton, S. C., \& Healy, S. D. (1990). Memory in foodstoring birds: Adaptive specialization in brain and behaviour? In G. M. Edelman, W. E. Gall, \& W. M. Cowan (Eds.), Signal and sense: Local and global order in perceptual maps (pp. 475-498). New York: Neuroscience Institute.

Krebs, J. R., Sherry, D. F., Healy, S. D., Perry, V. H., \& Vaccarino, A. L. (1989). Hippocampal specialization of food-storing birds. Proceedings of the National Academy of Sciences, 86, 1388-1392.

MACPHAIL, E. M. (1982). Brain and intelligence in vertrebrates. Oxford: Oxford University Press, Clarendon Press.

MacphaIL, E. M. (1993). The neuroscience of animal intelligence: From the seahare to the seahorse. New York: Columbia University Press.

Nadel, L. (1991). The hippocampus and space revisited. Hippocampus, 1, 221-229.

O'Boyle, V. J., Murray, E. A., \& Mishrin, M. (in press). Effects of excitotoxic amygdalo-hippocampal lesions visual recognition in rhesus monkeys. Society of Neuroscience Abstracts.

Olson, D. J. (1991). Species differences in spatial memory among Clark's nutcrackers, scrub jays and pigeons. Journal of Experimental Psychology: Animal Behavior Processes, 17, 363-376.

Olton, D. S., \& SAmuelson, R. J. (1976). Remembrance of places past: Spatial memory in rats. Journal of Experimental Psychology: Animal Behavior Processes, 2, 97-116.

Rawlins, J. N. P., Lyford, G. L., Seferiades, A., Deacon, R. M. J., \& CASSADAY, H. J. (1993). Critical determinants of nonspatial working memory deficits in rats with conventional lesions of the hippocampus or fornix. Behavioral Neuroscience, 107, 420-433.

ReIlly, S., \& Good, M. (1989). Hippocampal lesions and associative learning in the pigeon. Behavioral Neuroscience, 103, 731-742.

RICE, H. N. (1992). Food caching, simple association and spatial memory in the blackcapped chickadee. Unpublished master's thesis, University of Western Ontario.

Sandi, C., Rose, S. P. R., \& Patterson, T. A. (1992), Unilateral hippocampal lesions prevent recall of a passive avoidance task. Neuroscience Letters, 141, 255-258.

Shapiro, M. L., \& Olton, D. S. (in press). Hippocampal function and interference. In D. L. Schacter \& E. Tulving (Eds.), Memory systems 1994. Cambridge, MA: MIT Press.

Sherry, D. F., \& VACCARINO, A. L. (1989). Hippocampus and memory for food caches in black-capped chickadees. Behavioral Neuroscience, 103, 308-318.

Shettleworth, S. J. (1990). Spatial memory in food-storing birds. Philosophical Transactions of the Royal Society of London: Series $B, 329,143-151$.

Shettleworth, S. J., \& Krebs, J. R. (1982). How marsh tits find their hoards: Roles of site preferences and spatial memory. Journal of Experimental Psychology: Animal Behavior Processes, 8 , 354-375.

Shettleworth, S. J., Krebs, J. R., Healy, S. D., \& Thomas, C. M. (1990). Spatial memory of food storing tits: Comparisons of memory in storing and non-storing tasks. Journal of Comparative Psychology, 104, 71-81.

SQuire, L. R. (1992). Memory and the hippocampus: A synthesis from findings with rats, monkeys, and humans. Psychological Review, 99, 195-231.

SzeKely, A. D., \& Krebs, J. R. (1993). Target structures of the hippocampal projections in the zebra finch brain. Brain Research Association Abstracts, 10, 47.

(Manuscript received June 8, 1993; revision accepted for publication November 17, 1993.) 